\title{
Differential expression of nuclear lamins in normal and cancerous prostate tissues
}

\author{
ROSELLA CORADEGHINI ${ }^{1}$, PAOLA BARBORO ${ }^{1}$, ALESSANDRA RUBAGOTTI ${ }^{1,2}$, FRANCESCO BOCCARDO $^{1,2}$, \\ SILVIO PARODI ${ }^{1,2}$, GIORGIO CARMIGNANI $^{3}$, CRISTINA D'ARRIGO ${ }^{4}$, ELIGIO PATRONE $^{4}$ and CECILIA BALBI ${ }^{1}$ \\ ${ }^{1}$ Istituto Nazionale per la Ricerca sul Cancro; ${ }^{2}$ Dipartimento di Oncologia, Biologia e Genetica, \\ ${ }^{3}$ Dipartimento di Urologia, Università di Genova, Largo Rosanna Benzi 10, I-16132 Genova; \\ ${ }^{4}$ Istituto per lo Studio delle Macromolecole, Sezione di Genova, Via De Marini 6, I-16146 Genova, Italy
}

Received July 26, 2005; Accepted September 21, 2005

\begin{abstract}
The process of carcinogenesis is characterized by definite changes in the protein composition of the nuclear matrix. We have recently found that lamins form, in addition to the nuclear lamina, an intranuclear web of thin fibrils. This finding prompted us to address the question of whether changes in the expression of lamins occur in the course of tumor development. In prostate cancer, lamin B undergoes a significant increase; interestingly, its nuclear content strongly correlates with tumor differentiation. Moreover, all the lamins show reproducible alterations in the distribution of the isoelectric variants, suggesting that dephosphorylation events could trigger changes in the pattern of gene expression by inducing structural rearrangements of the nuclear scaffold.
\end{abstract}

\section{Introduction}

The nuclear matrix (NM), the protein scaffold which directs the folding of chromatin inside the interphase nucleus, plays a general role in the spatial and temporal coordination of gene activation events; therefore, changes in the gene expression pattern occurring in the course of carcinogenesis are expected to depend on the impairment of its regulatory functions $(1,2)$. As a fact, in all the tumor studied the NM shows specific structural and protein changes; the evolution toward the malignant phenotype is associated with the appearance of some new proteins and with the cessation of the expression of others (3). We have recently shown that the development of human prostate cancer $(\mathrm{PCa})$ is characterized by an increase in the complexity of the protein pattern of the NM. Poorly differentiated tumors express proteins that are not detected in more differentiated tumors $(4,5)$; moreover, a few newly expressed proteins are significantly correlated with the risk of biochemical progression (6).

Correspondence to: Dr Cecilia Balbi, National Cancer Research Institute, Largo Rosanna Benzi 10, I-16132 Genoa, Italy

E-mail: cecilia.balbi@istge.it

Key words: prostate cancer, lamins, nuclear matrix proteins
Until now, the lack of knowledge of the organization and protein composition of the scaffold has seriously hampered the identification of the functional consequences, if any, of the large nuclear and chromatin alterations occurring in transformed cells $(1,2,7)$. The number of copies per nucleus of the protein showing significant changes in PCa roughly corresponds to that of the scaffold associated regions of DNA (5), suggesting that these species represent fine modulating factors of gene activity. Thus, the question of whether structural components of the NM are involved in the control of cancer development $(1,8)$ remains unsolved. In 1994, Zeng et al (9) suggested that the nuclear mitotic apparatus protein (NuMA) is a major structural component of the nuclear skeleton; in 1995, Hozàk et al (10) reported the first evidence of the presence of lamins in the internal NM. Only in the last couple of years, however, have both the composition and structure of the internal NM been definitively characterized by high resolution electron and immunoelectron microscopy in our laboratory. Lamins are organized into a three-dimensional network of thin fibers which extend throughout the nucleus, whereas NuMA forms small islands anchored to the network; the stability of the internal NM strongly depends on the integrity of heterogeneous nuclear RNA $(8,11)$. These findings prompted us to characterize the changes in the structural proteins of the NM in PCa by quantifying first the expression of lamins. The results presented here demonstrate that, in $\mathrm{PCa}$, the expression of lamin B undergoes a significant increase correlated to the level of differentiation.

\section{Materials and methods}

Patients and tissue samples. PCa specimens were obtained from up to 37 patients undergoing radical retropubic prostatectomy for clinically localized prostate cancer. Normal prostate tissue (NT) specimens were obtained from the controlateral lobe to the cancer zone of 17 patients from the group reported above and from 3 additional patients undergoing prostate vesciculo cistectomy for bladder cancer. Tissues were immediately frozen in liquid nitrogen and stored until use, and were histologically confirmed by hematoxylin and eosin staining. The patient characteristics are summarized in Table I. The tumors were classified according to the TNM system and graded according to the criteria of Gleason (12). 
Table I. Main characteristics of prostate cancer patients.

\begin{tabular}{|c|c|c|}
\hline Variable & $\begin{array}{c}\operatorname{Lamin} \mathrm{A} / \mathrm{C} \\
\mathrm{n}(\%)\end{array}$ & $\begin{array}{l}\text { Lamin B } \\
\mathrm{n}(\%)\end{array}$ \\
\hline No. of patients & 32 & 37 \\
\hline $\begin{array}{l}\text { Median age in years } \\
\text { (range) }\end{array}$ & $\begin{array}{c}64 \\
(48-74)\end{array}$ & $\begin{array}{c}64 \\
(58-73)\end{array}$ \\
\hline $\begin{array}{l}\text { Median pre-treatment } \\
\text { PSA level in } \mathrm{ng} / \mathrm{ml} \text { (range) }\end{array}$ & $\begin{array}{c}11.6 \\
(5-50.1)\end{array}$ & $\begin{array}{c}10.6 \\
(5.0-37.7)\end{array}$ \\
\hline Gleason score $\geq 7$ & $21(65.6)$ & $23(62.2)$ \\
\hline \multicolumn{3}{|l|}{ Depth of invasion (T) } \\
\hline $\mathrm{T} 2$ & $18(56.3)$ & $23(62.2)$ \\
\hline $\mathrm{T} 3-4$ & $14(43.7)$ & $14(37.8)$ \\
\hline \multicolumn{3}{|l|}{ Lymph nodes $(\mathrm{N})$} \\
\hline N0 & $18(56.3)$ & $22(59.5)$ \\
\hline $\mathrm{N}+$ & $5(15.6)$ & $6(16.2)$ \\
\hline $\mathrm{Nx}$ & $9(28.1)$ & $9(24.3)$ \\
\hline Surgical margins involved & $13(40.6)$ & $14(37.8)$ \\
\hline Seminal vesicles involved & $8(25.0)$ & $8(21.6)$ \\
\hline $\begin{array}{l}\text { Neoadjuvant treatment } \\
\text { with hormones }\end{array}$ & $5(15.6)$ & $4(10.8)$ \\
\hline
\end{tabular}

Purification of the NM-Intermediate Filament Complex. The NM-Intermediate Filament (NM-IF) complex was isolated according to Alberti et al (5). Protein concentration was determined using the Bio-Rad protein microassay (Bio-Rad, München, Germany) with bovine serum albumin as the standard.

Gel electrophoresis. One-dimensional SDS-polyacrylamide gel electrophoresis (PAGE) was carried out according to Laemmli (13). Twenty $\mu \mathrm{g}$ of NM-IF proteins were loaded on two $10 \%$ PAGE and separated at $5 \mathrm{~mA} / \mathrm{gel}$ for $16 \mathrm{~h}$ at a constant temperature of $12^{\circ} \mathrm{C}$. One gel was stained with Coomassie brilliant blue R-250, the other used in the Western blot experiments. High resolution two-dimensional electrophoretic analysis was carried out as already described (14). In order to characterize changes in the isoforms of lamins, twodimensional gel electrophoresis was carried out using the Pharmacia Multiphor II system in the first dimension.

Immunodetection of lamins. Immunodetection of lamins was carried out as already described $(5,8)$ using the affinity-purified goat polyclonal antibodies, lamin A/C (N-18) diluted 1:200 and lamin B (C-20) diluted 1:150 (Santa Cruz Biotechnology Inc.). These antibodies recognize peptides mapping at the amino terminus of human lamins $\mathrm{A}$ and $\mathrm{C}$ and at the carboxy terminus of human lamin B1 and, to a lesser extent, lamin B2 and $\mathrm{B} 3$, respectively.

Determination of the relative amounts of lamins. Since the major components of the NM-IF complex undergo appreciable
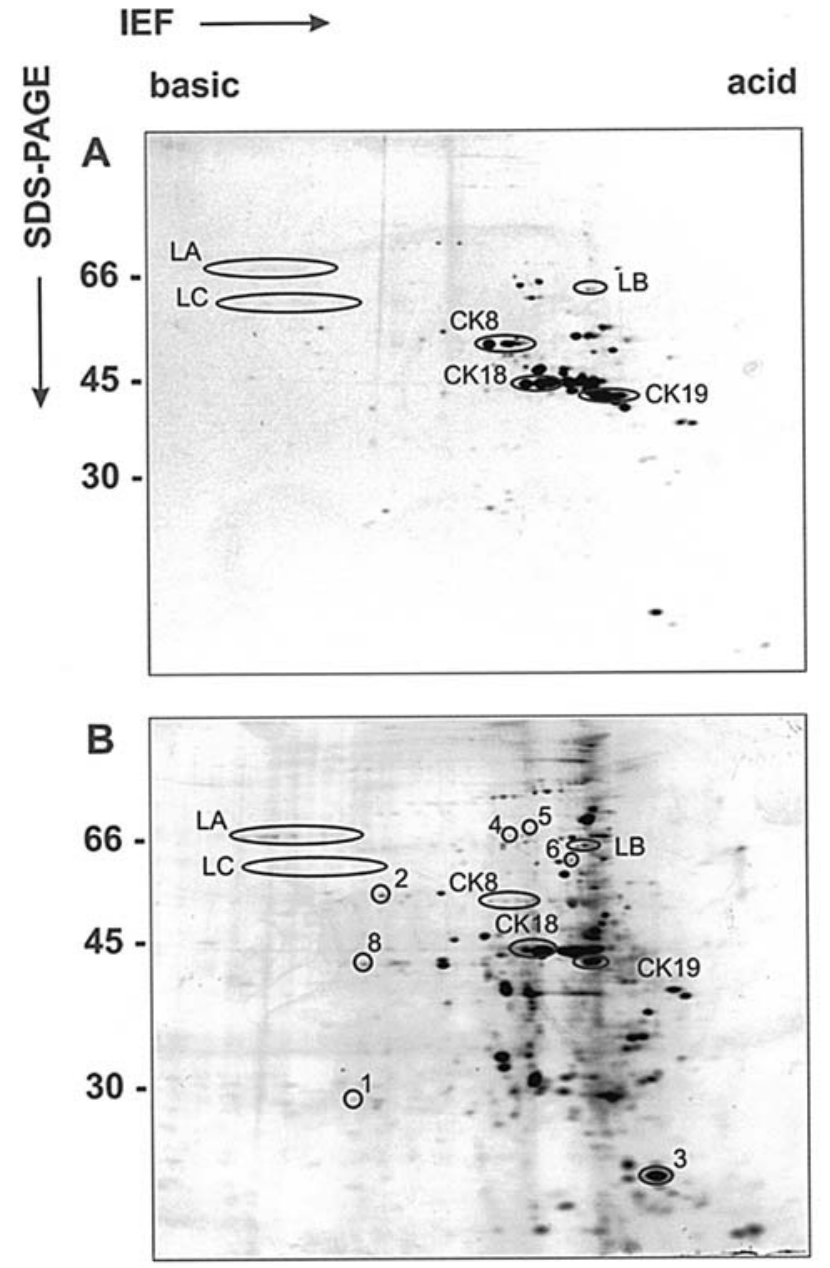

Figure 1. Two-dimensional electrophoretic analysis of the NM-IF complex of NT and PCa specimens from the same patient (A and B, respectively). (A) The thin lines enclose the major components of the cytoskeleton and the nuclear lamina. Ac, actin; LA, LB and LC, lamins A, B and C; V, vimentin; CK8, CK18 and CK19, cytokeratins 8, 18, 19. Tumor-associated NM proteins are marked by circles in $\mathrm{B}$ and identified with the same number used in Boccardo et al (6). The relative molecular weights of standard proteins in $\mathrm{kDa}$ are reported on the left. Silver-stained gels.

changes in expression during PCa development, it was not possible to use an internal control to ensure equal loading on the gels. Therefore, the relative amounts of type A and type B lamins were determined following the quantitative method described by Alberti et al (5). The relative intensity of the signal of each protein spot was obtained by normalizing the integrated optical density, obtained by an enhanced chemiluminescence assay kit (ECL), A for the integrated optical density of the corresponding Coomassie stained gel B. In order to reduce differences arising from fluctuations in the experimental conditions of the immunoblot, a fixed $(10 \mu \mathrm{g})$ amount of rat liver lamins from the same batch were run on the gels and the ratio A/B further normalized by the ECL signal of the lamin standard. This method allowed us to obtain quantitative results.

Statistical analysis. The correlation of the variables undergoing study (lamin relative amount, pre-operative PSA serum level, Gleason score, tumor size, nodal status surgical margin involved, seminal vescicles involved and neoadjuvant 
A

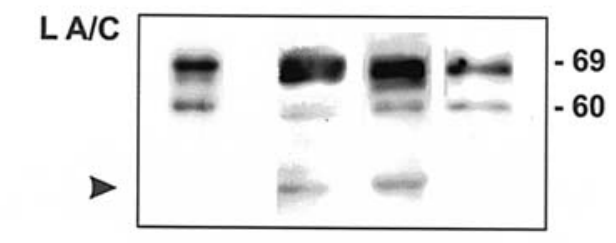

L B

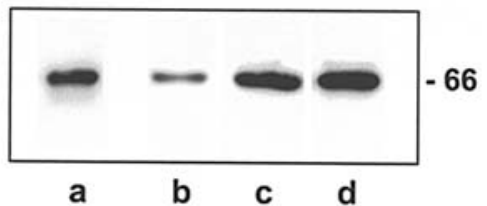

B

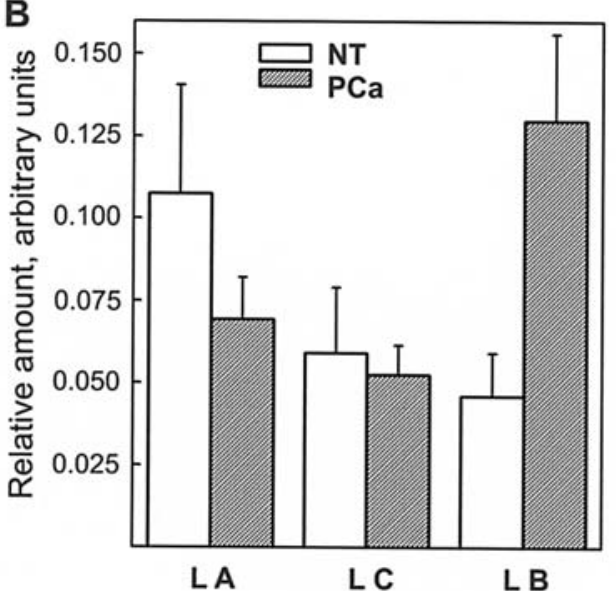

Figure 2. (A) Western blot analysis of the NM-IF complex isolated from NT (lane b) and two PCa specimens with Gleason score 6 and 8 (lanes $\mathrm{c}$ and d). Lamins isolated from rat hepatocytes are reported for comparison in lane a. A major proteolytic fragment of lamin $\mathrm{A} / \mathrm{C}$ is marked by an arrowhead. The relative molecular weights of lamins in $\mathrm{kDa}$ are reported on the right. (B) The comparison among the relative amounts of LA, LC and LB in NT and $\mathrm{PCa}$, respectively. The ordinates represent the mean $\pm \mathrm{SE}$.

treatment) were investigated by using the Pearson correlation coefficient. A comparison between NT and PCa was made using the independent Student's t-test. All of the P-values reported are two-sided; differences in the lamin content were considered statistically significant for $\mathrm{P} \leq 0.05$ (15). The statistical analyses were performed using the SPSS statistical software, version 9.0 (16).

\section{Results and Discussion}

Fig. 1 shows representative, high resolution two-dimensional gels of the NM-IF complex isolated from NT (A) and PCa, Gleason score 7 (B); the major cytoplasmic IF proteins and actin are indicated; tumor-specific NM proteins, as identified in previous reports $(5,6)$, are encircled. The large increase in the complexity of the NM composition in PCa can be immediately appreciated on eye inspection of the electrophoretic patterns. Lamins give rise to weakly stained spots as a consequence of the low concentration compared with that of major IF components and of the presence of several isoelectric variants.

Quantitation of the differences in the expression of individual lamins has been obtained by monodimensional immunoblot analysis. The experiments reported in Fig. 2A show that the use of anti-lamin N-18 and C-20 antibodies (see
Table II. Relative amounts of lamins in the NM-IF complex isolated from NT and PCa.

\begin{tabular}{lccc}
\hline & No. of patients & Mean \pm SE & P-value \\
\hline Lamin A & 17 & $0.107 \pm 0.033$ & 0.2 \\
NT & 32 & $0.069 \pm 0.012$ & \\
PCa & & & \\
Lamin C & 17 & $0.059 \pm 0.020$ & 0.5 \\
NT & 32 & $0.052 \pm 0.009$ & \\
PCa & & & \\
Lamin B & 20 & $0.048 \pm 0.014$ & 0.03 \\
NT & 37 & $0.128 \pm 0.026$ & \\
PCa & & & \\
\hline
\end{tabular}

Table III. Significance of the relationship between the relative amount of lamin B and patient characteristics.

\begin{tabular}{llc}
\hline Patient characteristics & P-value & $\begin{array}{c}\text { Pearson's correlation } \\
\text { coefficient }\end{array}$ \\
\hline Age & 0.1 & -0.240 \\
PSA & 0.3 & 0.181 \\
Gleason score & 0.001 & 0.521 \\
Deph of invasion & 0.5 & 0.106 \\
Lymph nodes & 0.1 & 0.283 \\
Surgical margins involved & 0.4 & -0.133 \\
Seminal vescicles involved & 0.2 & 0.230 \\
Neoadjuvant treatment & 0.9 & 0.023 \\
\hline
\end{tabular}

Materials and methods) results in a highly specific recognition of both lamins $\mathrm{A} / \mathrm{C}$ and $\mathrm{B}$. The arrow indicates a degradation fragment of type A lamin; this peptide has been detected also in NT samples, suggesting that proteolytic cleavage of lamins A and C can be a physiological process and could be associated to apoptotic cell death $(17,18)$. The relative amounts of lamins which remain associated with the NM are shown in Fig. 2B; the results of the statistical analysis are detailed in Table II. The relative amount of lamin B increases significantly $(\mathrm{P}=0.03)$ in $\mathrm{PCa}$ with respect to NT; the opposite trend is observed for both lamins $\mathrm{A}$ and $\mathrm{C}$ but the differences are not statistically significant. Finally, the data reported in Table III show that the increase in lamin B is strongly correlated with Gleason score. This finding indicates that the expression of this protein is differentiation related, as already noted for the minor components of the NM showing differences between tumor and normal tissue (4-6).

Differences in the expression of lamins between tumor and normal cells have been reported in several studies. As a rule, the expression of lamin $\mathrm{A} / \mathrm{C}$ was found to decrease in all tumor tissues or cell lines, while the observations on lamin B were limited to verifying that this protein was present (19-23). A major weakness of these studies has been the use of immunohistochemistry techniques, by which only a semi- 

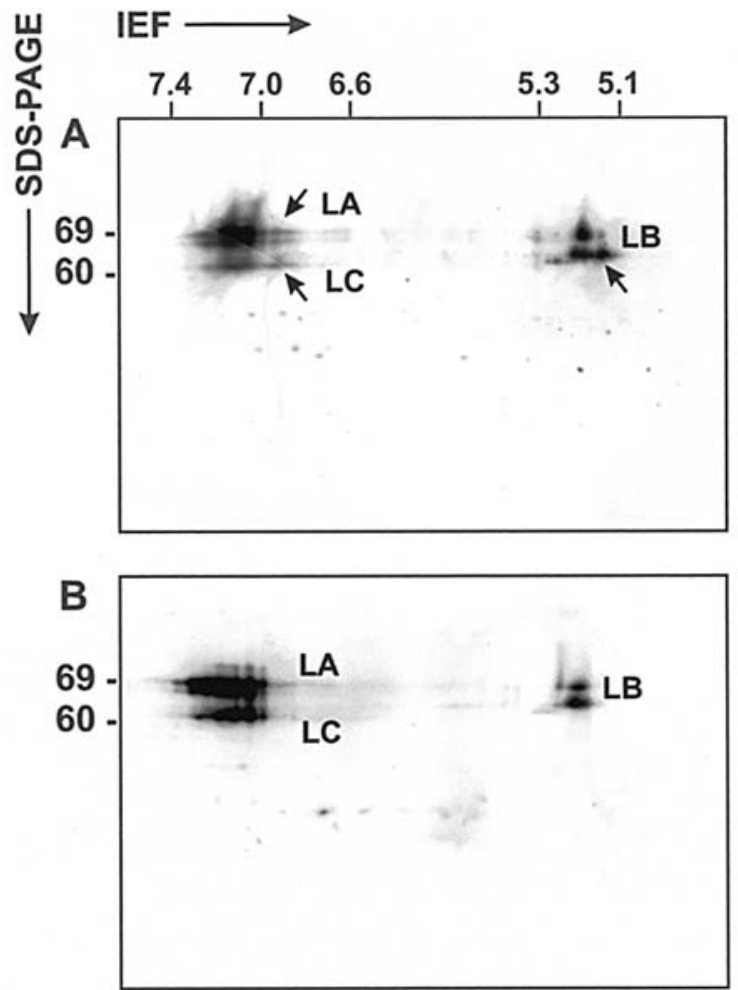

Figure 3. High resolution two-dimensional gel electrophoresis characterization of the isoelectric variants of lamins in NT (A) and PCa (B). Samples resolved by two-dimensional gel electrophoresis were transferred on PVDF membranes and probed with lamin $\mathrm{A} / \mathrm{C}$ and lamin $\mathrm{B}$ antibodies. The arrows in (A) indicate the more acidic variants of lamins which are lost in PCa.

quantitative evaluation of the staining intensity of nuclei in fixed tissue can be obtained. Therefore, it is difficult to compare these previous data with the results of our immunoblot assay. Our work indeed provides clear-cut evidence of a direct link between the expression of lamin B and cell differentiation.

In a recent study, we reported the protein and structural characterization of the internal nuclear matrix and stressed the possible functional role of the fibrillar intranuclear web (8). The latter consists of thin, 4-nm, lamin fibrils to which NuMA islands are anchored. Furthermore, these observations strongly suggest that RNA might directly mediate the anchoring of NuMA to the lamin scaffold. The lamin web is expected to be a highly dynamic structure involved both in the transition between eu and heterochromatin and in RNA synthesis and processing; fast rearrangements in its organization could be directed by changes in phosphorylation, as it occurs during the transition from late prophase to metaphase at the beginning of cell division (24). We therefore carried out a preliminary characterization of the changes in the phosphorylation of lamins in PCa by combining high resolution two-dimensional electrophoresis with immunoblot analysis. A representative electrophoretic pattern obtained for a PCa sample with Gleason score 6 is reported in Fig. 3B. In PCa, the more acidic isoforms of lamins undergo a significant decrease with respect to NT (Fig. 3A), directly showing the occurrence of a decrease in phosphorylation. Since proliferation should result in an increase in phosphorylation, the observed changes in the isoform distribution might actually reflect mechanistic features of cellular transformation.
Cytokeratins undergo large and definite changes with tumor progression both in the resistant hepatocyte model of hepatocarcinogenesis (14) and in PCa development (4,5). In a previous paper (14), we speculated that tumor associated chromatin rearrangement could arise from changes in the NM induced by cytoskeletal alterations, following the hypothesis of Ingberg and Folkman (25). Spencer and his colleagues (26) have shown that, in a hormone-dependent and estrogen receptor-positive human breast cancer cell line, cytokeratins 8,18 and 19 are associated with DNA, in confirmation of Ingberg's model. Alternatively, the three-dimensional architecture of both the lamina and the internal nuclear web could directly undergo rearrangements which could, in turn, affect the overall organization of the bulk of chromatin. Spann et al (27) used a dominant negative lamin mutant lacking the $\mathrm{NH}_{2}$ terminal domain to disrupt the normal organization of nuclear lamin; inhibition of RNA polymerase II activity was induced in both mammalian cells and transcriptionally active embryonic nuclei from Xenopus laevis. The present study, for the first time, establishes a direct link between structural changes in the nuclear scaffold and transcription, and stimulates future work on the molecular and structural changes lamins undergo in different tumor tissues.

\section{Acknowledgements}

This work was supported by Ministero della Salute (2001-ICS conv. 133; 2003-ICS conv. 137); Fondo per gli Investimenti della Ricerca di Base (FIRB) (Project RBAUO1Y3SN) and Ministero dell'Università e della Ricerca Scientifica e Tecnologica (MIUR) (project MM06575531).

\section{References}

1. Nickerson JA: Nuclear dreams: the malignant alteration of nuclear architecture. J Cell Biochem 70: 172-180, 1998.

2. Stein GS, Montecino M, van Wijnen AJ, Stein JL and Lian JB: Nuclear structure-gene expression interrelationships: implications for aberrant gene expression in cancer. Cancer Res 60: 2067-2076, 2000.

3. Davido $\mathrm{T}$ and Getzenberg RH: Nuclear matrix proteins as cancer markers. J Cell Biochem Suppl 35: 136-141, 2000.

4. Alberti I, Parodi S, Barboro P, Sanna P, Nicolò G, Allera C, Patrone E, Galli $\mathrm{S}$ and Balbi C: Differential nuclear matrixintermediate filament expression in human prostate cancer in respect to benign prostatic hyperplasia. Cancer Lett 109: 193-198, 1996.

5. Alberti I, Barboro P, Barbesino M, Sanna P, Pisciotta L, Parodi S, Nicolò G, Boccardo F, Galli S, Patrone E and Balbi C: Changes in the expression of cytokeratins and nuclear matrix proteins are correlated with the level of differentiation in human prostate cancer. J Cell Biochem 79: 471-485, 2000.

6. Boccardo F, Rubagotti A, Carmignani G, Romagnoli A, Nicolò G, Barboro P, Parodi S, Patrone E and Balbi C: Nuclear matrix proteins changes in cancerous prostate tissues and their prognostic value in clinically localized prostate cancer. Prostate 55: 259-264, 2003.

7. Barboro P, Pasini A, Parodi S, Balbi C, Cavazza B, Allera C, Lazzarini G and Patrone E: Chromatin changes in cell transformation: progressive unfolding of the higher-order structure during the evolution of rat hepatocyte nodules. A differential scanning calorimetry study. Biophys J 65: 1690-1699, 1993.

8. Barboro P, D'Arrigo C, Diaspro A, Mormino M, Alberti I, Parodi S, Patrone E and Balbi C: Unraveling the organization of the internal nuclear matrix: RNA-dependent anchoring of NuMA to lamin scaffold. Exp Cell Res 279: 202-218, 2002.

9. Zeng C, He D and Brinkley BR: Localization of NuMA protein isoforms in the nuclear matrix of mammalian cells. Cell Motil Cytoskeleton 29: 167-176, 1994. 
10. Hozàk P, Sasseville AM, Raymond Y and Cook PR: Lamin proteins form an internal nucleoskeleton as well as a peripheral lamina in human cells. J Cell Sci 108: 635-644, 1995.

11. Barboro P, D'Arrigo C, Mormino M, Coradeghini R, Parodi S, Patrone E and Balbi C: An intranuclear frame for chromatin compartmentalization and higher-order folding. J Cell Biochem 88: 113-120, 2003.

12. Rosai J: Member of the Department of Pathology, memorial Sloan-Kettering Cancer center. Standardized reporting of surgical pathology diagnoses for the major tumor types. A proposal. Am J Clin Pathol 100: 240-255, 1993.

13. Laemmli UK: Cleavage of structural proteins during the assembly of the head of bacteriophage T4. Nature 227: 680-685, 1970.

14. Barboro P, Alberti I, Sanna P, Parodi S, Balbi C, Allera C and Patrone E: Changes in the cytoskeletal and nuclear matrix proteins in rat hepatocyte neoplastic nodules in their relation to the process of transformation. Exp Cell Res 225: 315-327, 1996.

15. Fleiss JL: Statistical Methods for Rates and Proportions. 2nd edition. John Wiley \& Sons, New York, 1981.

16. SPSS: Professional Statistics, Version 9.0. SPSS Inc., Chicago, 1997.

17. Lazebnik YA, Takahashi A, Moir RD, Goldman RD, Poirier GG, Kaufmann SH and Earnshaw WC: Studies of the lamin proteinase reveal multiple parallel biochemical pathways during apoptotic execution. Proc Natl Acad Sci USA 92: 9042-9046, 1995.

18. Takahashi A, Alnemri ES, Lazebnik YA, Fernandes-Alnemri T, Litwack G, Moir RD, Goldman RD, Poirier GG, Kaufmann SH and Earnshaw WC: Cleavage of lamin A by Mch2 alpha but not CPP32: multiple interleukin 1 beta-converting enzyme-related proteases with distinct substrate recognition properties are active in apoptosis. Proc Natl Acad Sci USA 93: 8395-8400, 1996.
19. Kaufmann SH, Mabry M, Jasti R and Shaper JH: Differential expression of nuclear envelope lamins $\mathrm{A}$ and $\mathrm{C}$ in human lung cancer cell lines. Cancer Res 51: 581-586, 1991.

20. Kaufmann SH: Expression of nuclear envelope lamins A and C in human myeloid leukemias. Cancer Res 52: 2847-2853, 1992.

21. Cance WG, Chaudhary N, Worman HJ, Blobel G and CordonCardo C: Expression of the nuclear lamins in normal and neoplastic human tissues. J Exp Clin Cancer Res 11: 233-246, 1992.

22. Machiels BM, Broers JL, Raymond Y, De Ley L, Kuijpers HJ, Caberg NE and Ramaekers FC: Abnormal A-type lamin organization in a human lung carcinoma cell line. Eur J Cell Biol 67: 328-335, 1995.

23. Machiels BM, Ramaekers FC, Kuijpers HJ, Groenewoud JS, Oosterhuis JW and Looijenga LH: Nuclear lamin expression in normal testis and testicular germ cell tumors of adolescents and adults. J Pathol 182: 197-204, 1997.

24. Moir RD, Spann TP, Lopez-Soler RI, Yoon M, Goldman AE, Khuon S and Goldman RD: Review: the dynamics of the nuclear lamins during the cell cycle-relationship between structure and function. J Struct Biol 129: 324-334, 2000.

25. Ingber DE and Folkman J: Mechanochemical switching between growth and differentiation during fibroblast growth factor-stimulated angiogenesis in vitro: role of extracellular matrix. J Cell Biol 109: 317-330, 1989.

26. Spencer VA, Coutts AS, Samuel SK, Murphy LC and Davie JR: Estrogen regulates the association of intermediate filament proteins with nuclear DNA in human breast cancer cells. J Biol Chem 273: 29093-29097, 1998.

27. Spann TP, Goldman AE, Wang C, Huang S and Goldman RD: Alteration of nuclear lamin organization inhibits RNA polymerase II-dependent transcription. J Cell Biol 156: 603-608, 2002 . 